\title{
Relationship between PDGFR expression and the response to pazopanib in intimal sarcoma of the pulmonary artery: A case report
}

\author{
SATOSHI SAI $^{1}$, YOSHINORI IMAMURA ${ }^{1}$, NAOMI KIYOTA ${ }^{1,2}$, NAOE JIMBO $^{3}$, \\ MASANORI TOYODA $^{1}$, YOHEI FUNAKOSHI ${ }^{1}$, NAOKO CHAYAHARA ${ }^{1}$, YASUKO HYOGO ${ }^{1}$, \\ KEI TAKENAKA ${ }^{1}$, HIROTAKA SUTO ${ }^{1}$ and HIRONOBU MINAMI ${ }^{1,2}$
}

\author{
${ }^{1}$ Department of Medical Oncology/Hematology, Kobe University Hospital and Graduate School of Medicine; \\ ${ }^{2}$ Cancer Center, Kobe University Hospital; ${ }^{3}$ Department of Diagnostic Pathology, Kobe University Hospital and \\ Graduate School of Medicine, Kobe City, Hyogo 650-0017, Japan
}

Received May 30, 2020; Accepted September 15, 2020

DOI: $10.3892 / \mathrm{mco} .2020 .2168$

\begin{abstract}
Intimal sarcoma of the pulmonary artery (PAIS) is a rare disease with a poor prognosis. Pazopanib, which has been indicated in metastatic non-adipocytic soft-tissue sarcomas and is expected to be active in PAIS, is a multi-kinase inhibitor that targets the tyrosine kinase activity of vascular endothelial growth factor receptor (VEGFR), platelet-derived growth factor receptor (PDGFR) and stem cell factor receptor. The present study reports findings related to two cases of PAIS with PDGF and VEGF expression following treatment with pazopanib. A case with a moderate to strong expression of PDGFR- $\alpha$ and $-\beta$ presented a long-term stable disease when treated with pazopanib (progression-free survival, 5.8 months). In a second case with a weak expression of PDGFR- $\alpha$ and $-\beta$, the disease progressed rapidly on pazopanib (progression-free survival, 1.1 months). VEGFR-2 was not expressed in the tumors of both cases. The level of PDGFR expression in the tumor tissue may therefore be predictive of pazopanib efficacy.
\end{abstract}

\section{Introduction}

Intimal sarcoma of pulmonary artery (PAIS) is a rare disease which has a poor prognosis (1). PAIS is often diagnosed as advanced disease and has a high rate of postoperative recurrence. Although therapeutic options for PAIS are limited, several recent studies have reported that pazopanib, a multi-kinase inhibitor that targets vascular endothelial growth

Correspondence to: Dr Yoshinori Imamura, Department of Medical Oncology/Hematology, Kobe University Hospital and Graduate School of Medicine, 7-5-1 Kusunoki-cho, Chuo-ku, Kobe City, Hyogo 650-0017, Japan

E-mail: yimamura@med.kobe-u.ac.jp

Key words: case reports, intimal sarcoma, pazopanib, platelet-derived growth factor receptor, pulmonary artery, vascular endothelial growth factor receptor factor receptor (VEGFR)-1, -2, -3, platelet-derived growth factor (PDGF) receptor (PDGFR)- $\alpha,-\beta$ and stem cell factor receptor (c-Kit), shows activity in treatment for advanced vascular sarcomas, including PAIS (2-5). However, these previous reports did not investigate the relationship between the levels of PDGFR and VEGFR in tumor tissues and the response to pazopanib. Our present report provides new information in this regard, as we studied this relationship in two cases of PAIS.

\section{Case report}

Case 1. A 33-year-old man visited a local hospital with a chronic cough. A CT scan showed an intravascular lesion of the left pulmonary artery and multiple masses in the left lung. He underwent pneumonectomy of the left lung for tumor embolism and angioplasty of the left pulmonary artery. In addition to the clinical course, immunohistochemical analysis showed spinal tumor cells were positive for murine double minute 2 (MDM2) and CD34, which led to the final diagnosis of PAIS. Because the margin of the left pulmonary artery base was positive for tumor cells, adjuvant irradiation (60 Gy/30 fr) and adjuvant chemotherapy with doxorubicin and ifosfamide $\left(60 / 7,500 \mathrm{mg} / \mathrm{m}^{2} /\right.$ every 3 weeks, 1 cycle, AI therapy) were performed. However, recurrence was observed 2 months later. Pazopanib treatment was initiated and this stabilized the disease for 5.8 months, which is superior to the 2 months achieved with AI therapy. Subsequently, eribulin was administered, but a CT scan on day 14 of the 1st cycle showed rapid tumor growth, which was considered as flare-up upon the discontinuation of pazopanib. The patient died 2 months after the discontinuation of pazopanib, a total of 18 months after the diagnosis (Table I).

Immunohistochemistry revealed that tumor cells were moderately and strongly positive for PDGFR- $\alpha$ (Cell Signaling Technology, Inc.; cat. no. 3174; Fig. 1A) and PFGFR- $\beta$ (Abcam; cat. no. ab32570; Fig. 1B), respectively, but negative for VEGFR-2 (Cell Signaling Technology, Inc.; cat. no. 2479; Fig. 1C). 
A

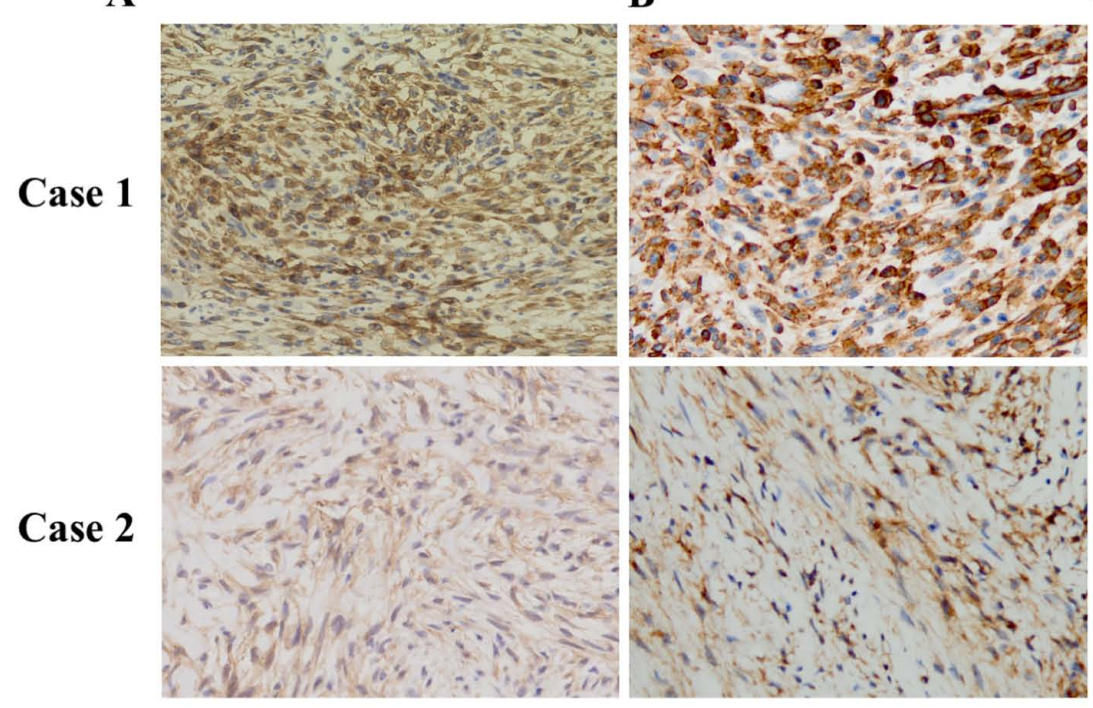

C

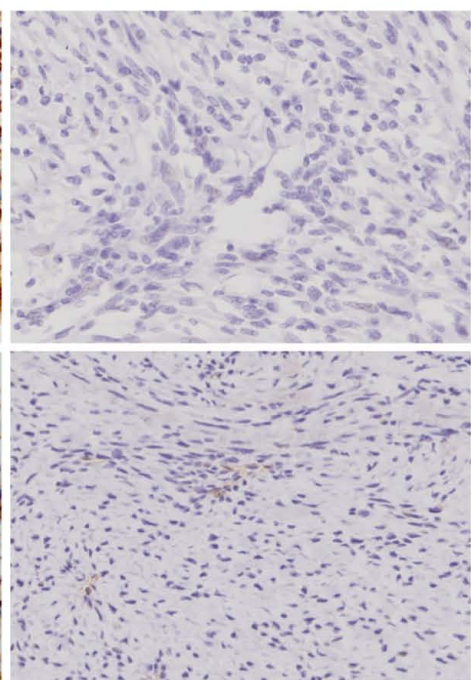

Figure 1. Immunohistochemistry staining (magnification, x200). (A) PDGFR- $\alpha$ (Cell Signaling Technology, Inc.; cat. no. 3174), (B) PDGFR- $\beta$ (Abcam; cat. no. 32570), (C) VEGFR-2 (Cell Signaling Technology, Inc.; cat. no. 2479). PDGFR, platelet-derived growth factor receptor; VEGFR, vascular endothelial growth factor receptor.

Case 2. A 44-year-old woman visited a local hospital with dyspnea on exertion, and a CT scan revealed an intravascular lesion of the left pulmonary artery and a mass in the right lung. She underwent right upper lobectomy and angioplasty of the left pulmonary artery. During postoperative recovery and preparation of therapy for the positive tumor cells at the resection margins, lung metastases developed 3 months after the surgery. Subsequently, palliative chemotherapy with doxorubicin $\left(60 \mathrm{mg} / \mathrm{m}^{2} /\right.$ every 3 weeks, 6 cycles) followed by eribulin $\left(1.4 \mathrm{mg} / \mathrm{m}^{2} /\right.$ every 3 weeks, 2 cycles) were administered sequentially, but neither treatments induced a response. Nine months after the diagnosis, pazopanib was initiated as a 3rd-line palliative pharmacotherapy. However, CT scans one month after the start of pazopanib revealed an increased tumor size. The patient died 14.3 months after the original diagnosis (Table I).

Immunohistochemistry revealed that the tumor cells were weakly positive for PDGFR- $\alpha$ (Fig. 1A) and PDGFR- $\beta$ (Fig. 1B), and negative for VEGFR-2 (Fig. 1C). Immunostaining was performed according to the following protocol. Paraffin sections of tumor tissues of pulmonary artery were subjected to immunohistochemical staining for the PDGFR- $\alpha,-\beta$, VEGFR-2. At first, blocked specimen in blocking buffer for $1 \mathrm{~h}$ at room temperature. Blocking solution was removed and diluted primary antibodies were added (PDGFR- $\alpha$ : Cell Signaling Technology cat. no. 3174; PDGFR- $\beta$ : Abcam cat. no. ab32570; VEGFR-2: Cell Signaling Technology cat. no. 3174 ) and incubated overnight at $4{ }^{\circ} \mathrm{C}$. Antibody solution was removed and the incubated specimen was mixed with fluorochrome-conjugated secondary antibody for 1-10 min at room temperature.

\section{Discussion}

Through two cases of PAIS, the relationship between the expression of PDGFR or VEGFR and the response to pazopanib was investigated (Table I). In case 1, the tumor cells were strongly positive for PDGFR- $\beta$ (Fig. 1B) and moderately positive for PDGFR- $\alpha$ (Fig. 1A). Time to progression before pazopanib was two months, but pazopanib treatment stabilized the tumor for 5.8 months. In the second case, the tumor cells were weakly positive for PDGFR- $\alpha$ (Fig. 1A) and PDGFR- $\beta$ (Fig. 1B), which may explain the reduced response to treatment. Time to progression on pazopanib treatment was 1.1 months, while it took 3 months to progress after the surgery. Both cases were negative for expression of VEGFR-2 (Fig. 1C). Focusing on these two cases, high levels of PDGFR in tumor tissues might have contributed to an improved response to pazopanib treatment.

Compared to placebo, pazopanib significantly improved PFS (median PFS, 4.6 months vs. 1.6 months) in patients with metastatic non-adipocytic soft-tissue sarcoma (6). According to a European Organization for Research and Treatment of Cancer (EORTC) retrospective analysis of pazopanib in patients with advanced vascular sarcoma, the median PFS and OS were 3.0 and 9.9 months, respectively. In this analysis, among the 40 patients with vascular sarcoma, 2 (3.8\%) had intimal sarcomas and both of these patients demonstrated a partial response (2). Unfortunately, the number of PAIS cases in this previous report was too low to investigate the relationship between PDGFR and VEGFR expression in tumor tissue and the response to pazopanib. To the best of our knowledge, this is the first study to demonstrate the relationships between PDGFR and VEGFR expression and the response to pazopanib.

Although pazopanib is a multi-kinase inhibitor (1), our results suggest that the activity against PDGF may account for its activity in PAIS. This is consistent with the role of PDGFs in other malignancies. PDGFs bind to PDGFR- $\alpha$ and $-\beta$, and trigger cell proliferation, migration and differentiation. In humans, abnormal PDGF/PDGFR signaling has been associated with numerous malignant tumors, including activating mutations of PDGFR- $\alpha$ in gastrointestinal stromal tumors and the overexpression of PDGFR- $\beta$ in dermatofibrosarcoma protuberans $(7,8)$. In addition to hematological tumors, 
PDGFR- $\beta$ alterations are also involved in myofibromas, suggesting an oncogenic role in mesenchymal tumors (9). Amplifications of PDGFR- $\alpha$, PDGFR- $\beta$, c-Kit, MDM 2 and epidermal growth factor receptor (EGFR) have been seen in intimal sarcoma (7,9-12). Alterations in the PDGF/PDGFR signaling pathway, particularly PDGFR- $\alpha$ and PDGFR- $\beta$, may play an important role in the pathogenesis of intimal sarcoma $(9,10)$, with amplification and co-activation of both PDGFR- $\alpha$ and PDGFR- $\beta$ being observed frequently in intimal sarcoma, whereas KIT levels were similar to those in normal tissue. Consistent with the above, PDGFR, EGFR and MDM2 have all been proposed as therapeutic targets in intimal sarcoma $(9,10)$. Although early clinical trials have shown that the anti-PDGFR antibody olaratumab has antitumor activity in advanced soft-tissue sarcoma $(13,14)$, a recent phase III study failed to demonstrate an additional effect of olaratumab when combined with doxorubicin in soft tissue sarcoma (15). However, PAIS was not included in the phase III study, and the role of PDGFR inhibitors in PAIS warrants further investigation. We did not observe expression of VEGFR-2 in our patients, and no previous reports have found raised levels of VEGFR in intimal sarcoma. We thus infer that VEGFR does not play an important role in PAIS pathogenesis.

Interpretation of our present study is limited, as the small case number precludes statistical analysis. Furthermore, in case 1, pazopanib was used as a first-line treatment, whereas in case 2 , it was used as a third-line treatment; this does not allow a simple comparison of PFS in order to evaluate pazopanib efficacy. In addition, factors other than PDGFR and VEGFR expression are likely to determine the response to pazopanib. Allowing for these limitations, however, the strength of this study is that we evaluate the relationship between PDGFR expression and the therapeutic effect of pazopanib, in contrast to previous studies. In future studies, the relationship between the expression levels of PDGFR expression and the response to pazopanib needs to be verified with a larger sample population.

In conclusion, the present data suggest that PDGFR expression might be a potential predictor for the prediction of pazopanib efficacy.

\section{Acknowledgements}

Not applicable.

\section{Funding}

Not applicable.

\section{Availability of data and materials}

All data generated or analyzed during this study are included in this published article.

\section{Authors' contributions}

YI and SS made substantial contributions to the conception and design of the study. YH, KT and HS made substantial contributions to the acquisition of the data. SS drafted the manuscript. YI, NK, MT, YF, NC, YH, KT, HS, NJ and HM made substantial contributions to the analysis and interpreta- 
tion of the data and were involved in revising the manuscript critically for important intellectual content. NJ performed the immunohistochemistry staining of intimal sarcoma of the pulmonary artery. All authors read and approved the final manuscript.

\section{Ethics approval and consent to participate}

Not applicable.

\section{Patient consent for publication}

Informed consent for publication of this case report was obtained from patients.

\section{Competing interests}

The authors declare that they have no competing interests.

\section{References}

1. Krüger I, Borowski A, Horst M, de Vivie ER, Theissen P and Gross-Fengels W: Symptoms, diagnosis, and therapy of primary sarcomas of the pulmonary artery. Thorac Cardiovasc Surg 38: 91-95, 1990.

2. Kollár A, Jones RL, Stacchiotti S, Gelderblom H, Guida M, Grignani G, Steeghs N, Safwat A, Katz D, Duffaud F, et al: Pazopanib in advanced vascular sarcomas: An EORTC soft tissue and bone sarcoma group (STBSG) retrospective analysis. Acta Oncol 56: 88-92, 2017.

3. Schur S, Hamacher R and Brodowicz T: Pazopanib in primary cardiac angiosarcoma of the right atrium: A case report. Case Rep Oncol 9: 363-367, 2016.

4. Yoo KH, Kim HS, Lee SJ, Park SH, Kim SJ, Kim SH, La Choi Y, Shin KH, Cho YJ, Lee J and Rha SY: Efficacy of pazopanib monotherapy in patients who had been heavily pretreated for metastatic soft tissue sarcoma: A retrospective case series. BMC Cancer 15: 154, 2015.

5. Nakamura Y, Toda K, Miyagawa S, Yoshikawa Y, Hata H, Domae K, Matsuura R and Sawa Y: Surgical resection and pazopanib treatment for recurrent cardiac angiosarcoma. Clin Pathol 12: 2632010X19831261, 2019.

6. van der Graaf WT, Blay JY, Chawla SP, Kim DW, Bui-Nguyen B, Casali PG, Schöffski P, Aglietta M, Staddon AP, Beppu Y, et al: Pazopanib for metastatic soft-tissue sarcoma (PALETTE): A randomised, double-blind, placebo-controlled phase 3 trial. Lancet 379: 1879-1886, 2012.
7. Dewaele B, Floris G, Finalet-Ferreiro J, Fletcher CD, Coindre JM, Guillou L, Hogendoorn PC, Wozniak A, Vanspauwen V, Schöffski P, et al: Coactivated platelet-derived growth factor receptor $\{$ alpha\} and epidermal growth factor receptor are potential therapeutic targets in intimal sarcoma. Cancer Res 70: 7304-7314, 2010.

8. Sirvent N, Maire G and Pedeutour F: Genetics of dermatofibrosarcoma protuberans family of tumors: From ring chromosomes to tyrosine kinase inhibitor treatment. Genes Chromosomes Cancer 37: 1-19, 2003.

9. Ito Y, Maeda D, Yoshida M, Yoshida A, Kudo-Asabe Y, Nanjyo H, Izumi C, Yamamoto $\mathrm{F}$, Inoue $\mathrm{M}$, Shibata $\mathrm{H}$, et al: Cardiac intimal sarcoma with PDGFR $\beta$ mutation and co-amplification of PDGFR $\alpha$ and MDM2: An autopsy case analyzed by whole-exome sequencing. Virchows Arch 471: 423-428, 2017.

10. Tamborini E, Casieri P, Miselli F, Orsenigo M, Negri T, Piacenza C, Stacchiotti S, Gronchi A, Pastorino U, Pierotti MA and Pilotti S: Analysis of potential receptor tyrosine kinase targets in intimal and mural sarcomas. J Pathol 212: 227-235, 2007.

11. Bode-Lesniewska B, Zhao J, Speel EJ, Biraima AM, Turina M, Komminoth P and Heitz PU: Gains of 12q13-14 and overexpression of $\mathrm{mdm} 2$ are frequent findings in intimal sarcomas of the pulmonary artery. Virchows Arch 438: 57-65, 2001.

12. Tajima S, Takanashi Y, Takahashi $T$ and Neyatani H: Intimal sarcoma of the abdominal aorta with platelet-derived growth factor receptor $\alpha$ overexpression and amplification in mural invasive cells and pulmonary metastatic cells but not in intimal spreading cells. Pathol Int 65: 426-431, 2015.

13. Tap WD, Jones RL, Van Tine BA, Chmielowski B, Elias AD, Adkins D, Agulnik M, Cooney MM, Livingston MB, Pennock G, et al: Olaratumab and doxorubicin versus doxorubicin alone for treatment of soft-tissue sarcoma: An open-label phase $1 \mathrm{~b}$ and randomised phase 2 trial. Lancet 388: 488-497, 2016.

14. Yonemori K, Kodaira M, Satoh T, Kudo T, Takahashi S, Nakano K, Ando Y, Shimokata T, Mori J, Inoue K, et al: Phase 1 study of olaratumab plus doxorubicin in Japanese patients with advanced soft-tissue sarcoma. Cancer Sci 109: 3962-3970, 2018.

15. Tap WD, Wagner AJ, Schöffski P, Martin-Broto J, Krarup-Hansen A, Ganjoo KN, Yen CC, Abdul Razak AR, Spira A, Kawai A, et al: Effect of doxorubicin plus olaratumab vs. doxorubicin plus placebo on survival in patients with advanced soft tissue sarcomas: The ANNOUNCE randomized clinical trial. JAMA 323: 1266-1276, 2020.

(i) $\ominus$ This work is licensed under a Creative Commons Attribution-NonCommercial-NoDerivatives 4.0 International (CC BY-NC-ND 4.0) License. 